\title{
EL DOMINIO DEL MONASTERIO DE SAN JULIAN DE SAMOS EN EL SIGLO XIV (1325-1380)
}

\author{
por \\ MARTA GONZÁLEZ VÁZQUEZ
}

En el estudio de la realidad de la Edad Media gallega tiene una especial importancia el conocimiento del señorío eclesiástico, que cubre toda su geografía. Primero Cluny y luego Císter irán asentándose en la región, dejando improntas todavía reconocibles en sus formas de vida y características sociales. La aproximación a ese papel de primera magnitud del monasterio en relación con los otros habitantes del espacio sobre el que ejerce su influencia, y en especial con el campesinado, es el que hace al tema atractivo e interesante, siendo numerosas las aportaciones y los ejemplos concretos.

El presente estudio no es por tanto ni original ni novedoso, sino tan sólo una contribución más, a través del monasterio de San Julián de Samos y su documentación, al conocimiento de una etapa que consideramos fundamental, ese siglo XIV crítico y aún ampliamente desconocido․

Junto a la limitación geográfica de nuestro estudio, ha sido necesaria una limitación cronológica, no impuesta por la documentación, sino por el haber sido estudiado ya el monasterio de Samos en una memoria de licen-

\footnotetext{
${ }^{1}$ El presente artículo es un extracto de mi Memoria de Licenciatura, realizada bajo la dirección del Dr. D. Ermelindo Portela Silva, en el Área de Historia Medieval del Departamento de Historia II de la Facultad de Geografía e Historia de la Universidad de Santiago.
}

"CUADERNOS DE ESTUDIOS GALLEGOS", Tomo XXXIX, Fascículo 104, Santiago 1991. 
ciatura $^{2}$ cuyas conclusiones deberán ser revisadas, al haber sido publicado recientemente el Tumbo de Samos, que permitirá sin duda ampliar nuestra información sobre la historia samanense en estos primeros siglos ${ }^{3}$.

Las fuentes utilizadas para el presente trabajo proceden en su totalidad del fondo documental del monasterio de San Julián de Samos, en la actualidad conservados en el Archivo Histórico Nacional (citado A.H.N.). Se trata de 200 pergaminos, que contienen un total de 240 documentos, con la salvedad de unos 32 que, a pesar de estar clasificados con la documentación del monasterio de Samos, pertenecen en realidad al de Santa María de Ferreira de Pallares. Es la propia naturaleza de la documentación utilizada la que nos obliga a hacer ciertas precisiones; sin lugar a dudas los archivos monásticos nos proporcionan uno de los medios esenciales para el estudio de la realidad medieval ${ }^{4}$; pero también la uniformidad de su contenido nos impide el plantearnos muchas cuestiones esenciales para el conocimiento de esa realidad. Son los aspectos relacionados con el dominio monástico -su formación, su consolidación, su conservación- los que proporcionan la única documentación a nuestro alcance, compuesta, por tanto, por compraventas de tierras y sus respectivos contratos agrarios en su mayor parte, pasando a primer y único plano el tema de la explotación del terrazgo y sus formas. El análisis presentado responde por tanto al proceso de la estructuración del dominio del monasterio, tanto en los bienes que formaban parte de su patrimonio desde el primer momento de su expansión geográfica, proceso que comienza en el siglo IX ${ }^{5}$, como en aquellos que adquirirá a mediados de la centuria que nos ocupa; sus características y las causas de su acumulación serán objeto de estudio en los apartados siguientes.

\section{EL DOMINIO ANTES DEL SIGLO XIV}

\section{a) Su extensión}

El proceso de formación del dominio monástico, proceso iniciado en fecha incierta, sufre, siguiendo la tónica general de la evolución de los señoríos monásticos, una ralentización importante en los mecanismos tradi-

${ }^{2}$ Rodriguez Cancio, M ${ }^{\mathrm{a}} \mathrm{R} .:$ Formación, consolidación y evolución del dominio de San Julián de Samos en los siglos IX al XIV (850-1325). Santiago, Universidad, 1978, inédita.

${ }^{3}$ Lucas Álvarez, Manuel: El tumbo de San Julián de Samos (siglos VIII-XII). Santiago, Publicaciones de la Caixa Galicia, 1986.

${ }^{4}$ García García, Ma Elida.: San Juan Bautista de Corias. Historia de un señorío monástico asturiano (siglos X-XV). Oviedo, Universidad, 1980, pag. 11.

${ }^{5}$ Rodríguez Cancio, Mª R.: op.cit., pag. 35. 


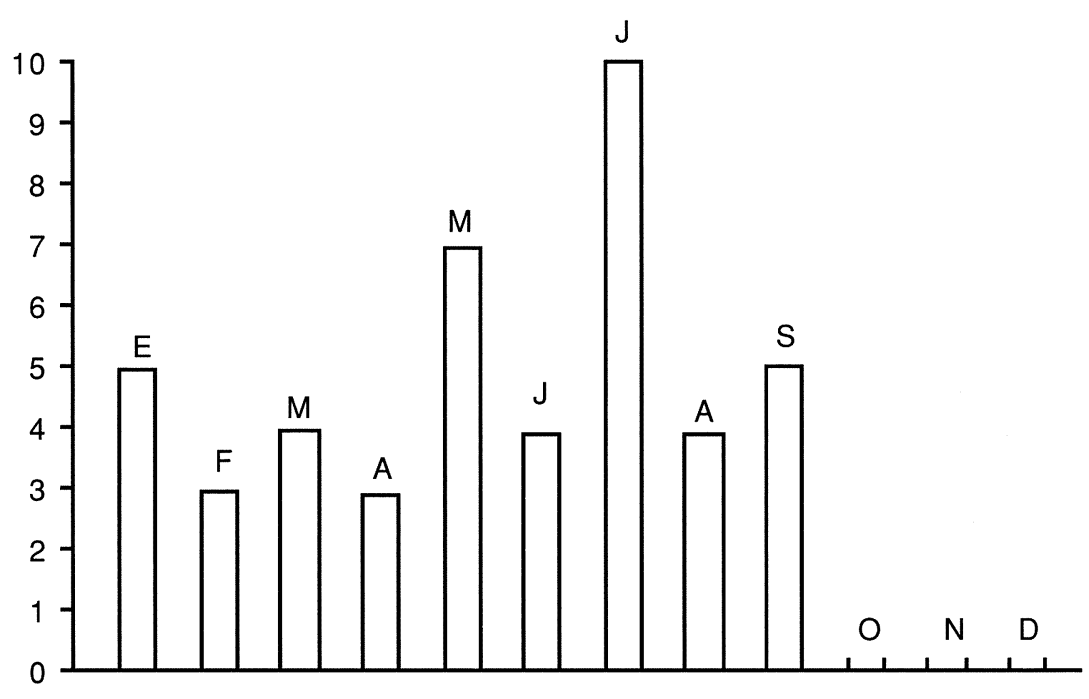

Evolución estacional de las compras

cionales de incorporación de nuevas propiedades. Las donaciones reales, nobiliarias, particulares procedentes de pequeños propietarios, desaparecen casi por completo, después de haber sido la principal fórmula para la ampliación del patrimonio monástico durante los siglos anteriores al que nos ocupa, especialmente hasta el siglo XII. Este proceso es común a la mayor parte de los monasterios benedictinos gallegos ${ }^{6}$ y también a aquéllos, más estudiados, cistercienses. Tal es el caso del monasterio de Santa María de Sobrado, estudiado por $\mathbf{M}^{\mathbf{a}}$ Carmen Pallares. Para la autora, esta estabilización es consecuencia del logro, por parte del monasterio, de su óptima extensión ${ }^{7}$. No se trata, tampoco, de un cambio de la situación económica gallega, ya que otros monasterios -caso de Santa María de Oya- escapan a esta cronología que establece el período de estabilización del patrimonio monástico hacia mediados del siglo XIII ${ }^{8}$.

En el marco de la situación general de la Península en el siglo XIV, sí podemos hablar de una incidencia de estos factores de crisis, así caracterizados por García de Cortázar, "temporales, epidemias, impuestos excesi-

${ }^{6}$ Portela Silva, E.: La colonización cisterciense en Galicia (1142-1250). Santiago, Universidad, 1981, pag. 37.

${ }^{7}$ Pallares Méndez, M C.: El monasterio de Sobrado: un ejemplo del protagonismo monástico en la Galicia medieval. La Coruña, Publicaciones de la Diputación, 1979, pag. 145.

${ }^{8}$ Pallares Méndez, Mํ C. Y Portela Silva, E. : El bajo valle del Miño en los siglos XII y XIII. Economía agraria y estructura social. Santiago, Universidad, 1971, pag. 81.

"CUADERNOS DE ESTUDIOS GALLEGOS", Tomo XXXIX, Fascículo 104, Santiago 1991. 
vos, guerras frecuentes, circulación de mala moneda, abusos de hombres poderosos, bandolerismo"9 en el desarrollo y características del señorío del monasterio de Samos. O, al menos, esto es lo que intentaremos en este trabajo. Antes de conocer la incidencia de estos factores de crisis, debemos intentar conocer a grandes rasgos el nacimiento y desarrollo de este dominio territorial.

Rodríguez Cancio, en la documentación por ella estudiada, considera la existencia de tres etapas en la formación y consolidación del dominio de Samos: una primera etapa, de los orígenes, inciertos, hasta el siglo XII, caracterizada por una extensión territorial amplia, una segunda etapa, de consolidación y de inicio de un señorío jurisdiccional, que abarca la totalidad del siglo XII, y la tercera etapa, de 1200 a 1325 , con una nueva expansión territorial dirigida por el monasterio conscientemente hacia ciertas zonas de interés particular, a través del mecanismo de las compras.

Tres puntos geográficos se perfilan como los centros de la expansión del monasterio durante este período: el núcleo de Samos y sus aledaños, que concentra la mayor cantidad de posesiones, la comarca del Bierzo, con centro en Villela, zona en la que el monasterio parece encontrarse directamente interesado por razones económicas -el cultivo de la vid- y por la misma razón, la zona de Quiroga, en la que el clima más templado permitiría también la existencia de cultivos de huerta ${ }^{10}$. En todas estas zonas, sin embargo, la producción esencial es el cereal, básico para las necesidades del monasterio.

La documentación estudiada por Maximino Arias nos ofrece un punto interesante para el conocimiento de la importancia y extensión de las propiedades de Samos a la altura de 1167; se trata de la carta de concordia entre el abad Sancho y los monjes del monasterio para el reparto de las rentas entre la mesa del abad y la de los monjes. Los bienes de la mesa abacial pasan a ser administrados directamente por el abad y aquéllos conventuales se distribuyen en un conjunto de oficios. Con este fin se presenta una minuciosa relación de los bienes que Samos posee, con sus rentas y el fin que se dará a éstas desde el momento de la concordia. La lista es prolija en detalles ${ }^{11}$, pero nos parece interesante el resaltar la cantidad de mijo que el abad entregará cada agosto al prior, cien modios, que el prior podrá cambiar en trigo. Muy pocos años después otro documento importante, la bula concedida por el papa Alejandro III al abad de Samos

${ }^{9}$ Garcia de Cortázar, J.A. : La época medieval. Madrid, Alianza Editorial, 1973, pag. 377.

${ }^{10}$ Rodriguez Cancio, Ma R.: op.cit. pag. 106.

11 Arias, M. "El monasterio de Samos durante los siglos XI y XII", en Archivos Leoneses, $\mathrm{n}^{\mathrm{0}} 73,1983$, pags. 50-51.

"CUADERNOS DE ESTUDIOS GALLEGOS", Tomo XXXIX, Fascículo 104, Santiago 1991. 
en 1175, nos permite conocer el número de iglesias sobre las cuales el monasterio ejerce algún tipo de derecho: son 81 iglesias completas y 12 fracciones ${ }^{12}$, de las cuales el monasterio cobra diezmos y primicias. Las cifras de ambos textos no parecen dejar lugar a dudas sobre la prosperidad del cenobio a fines del siglo XII.

\section{b) Formas de explotación}

La gran propiedad de los patrimonios monásticos en la región gallega se constituye fundamentalmente en un proceso paralelo a la desmembración e incluso desaparición en algunos casos de la gran propiedad nobiliar, a través del mecanismo de las donaciones. Samos no escapa tampoco a ese esquema general ${ }^{13}$ que continúa hasta el siglo XII, en el que se observa un descenso en el ritmo de los bienes anexionados al monasterio.

Esta gran propiedad se constituye esencialmente en villae y heredades. Estas villae parecen responder al esquema de villae-aldea ${ }^{14}$ estudiado por $\mathrm{M}^{\mathrm{a}} \mathrm{C}$. Pallares, y mantienen sus características originales anteriores a su incorporación al dominio del monasterio al menos hasta finales del siglo XII: la primera mención de fragmentación del terrazgo perteneciente a esas villae aparece en 1170, con una cesión de tierras en régimen de foro. Con este cambio el monasterio se convierte en una entidad recaudadora de rentas. La cesión de parte de las propiedades para su explotación por parte de los campesinos de la zona es algo común y casi obligado dada la extensión de las propiedades del cenobio: es por tanto difícil el aceptar que el monasterio no haya acudido anteriormente a 1170 a contratos de arriendo para poner en explotación parte de sus tierras. La falta de documentación que nos oriente en torno a estas posibles cesiones puede deberse a la existencia de acuerdos orales para estos arriendos anteriores a 1170 .

\section{c) Administración del dominio}

Directamente relacionado con el proceso de acumulación de propiedades por parte del monasterio y con la amplia extensión que éstas alcanzan en torno al siglo XIII, está la aparición en Samos del sistema administrativo de las obediencias u ovenças, según la terminología de la documentación monasterial. Se trata de un sistema en principio creado por los monjes cluniacenses, y que fue implantado hacia fines del siglo XII por varios monasterios benedictinos ${ }^{15}$. Rodriguez Cancio lo documenta en

12 Rodriguez Cancio, Ma․: op. cit. pag. 61.

${ }^{13}$ Rodriguez Cancio, M ${ }^{\mathrm{a}}$.R: op. cit. pag. 70.

${ }^{14}$ Pallares Méndez, $\mathrm{M}^{\mathrm{a}} \mathrm{C} .:$ El monasterio de Sobrado... pag. 38. 
Samos por primera vez en 1244 , funcionando normalmente ${ }^{16}$, lo que nos hace suponer que su aparición es bastante anterior.

Este sistema administrativo supone una separación no tan sólo de funciones entre los miembros de la comunidad, sino también una separación de las rentas, de las cuales se conseguiría una mejor distribución y aprovechamiento: un monje concreto se encargará de una obediencia u ovença particular. Estas, en el caso de Samos, son de dos tipos:

-ovenças que podemos equiparar a oficios, tales como la de la Albergaría, o la de la Enfermeria. El monje encargado de esta ovença estaría encargado también de administrar las rentas anejas al oficio.

-ovenças como circunscripciones territoriales, con un monje ovençal a su cargo, con funciones claramente recaudadoras, tanto de rentas en especie como en dinero. Debemos suponer también una mejora en el sistema de percepción de estas rentas, al hacerse más complejo y completo el sistema administrativo del monasterio.

\section{LA EXTENSIÓN DEL DOMINIO.}

\section{SUS TRANSFORMACIONES EN EL SIGLO XIV.}

\section{a) Formas de adquisición de los bienes.}

A pesar de la rarificación de los mecanismos más comunes de ampliación del domino, el proceso de formación de éste no se interrumpe con la entrada en el nuevo siglo y las nuevas características que éste supone. $\mathrm{Ca}$ -

\begin{tabular}{|l|c|c|c|c|c|c|c|}
\hline \multicolumn{7}{|c|}{ ADQUISICIONES (1325-1380) } \\
\hline & $1325-29$ & $1330-39$ & $1340-49$ & $1350-59$ & $1360-69$ & $1370-80$ & TOTAL \\
\hline DONACIONES & 2 & & 2 & 6 & & & 10 \\
\hline COMPRAS & & 1 & 31 & 13 & 1 & & 46 \\
\hline PERMUTAS & 1 & 1 & & & & 1 & 3 \\
\hline TOTAL & 3 & 2 & 33 & 19 & 1 & 1 & 59 \\
\hline
\end{tabular}

${ }^{15}$ Garcia Garcia, Ma E.: op. cit. pag. 374.

${ }^{16}$ Rodriguez Cancio, MâR.: op. cit. pag. 121. 
racterísticas generalizadas para el conjunto del contexto europeo con el nombre de crisis del siglo XIV, una denominación que encierra realidades bastante diferentes y que en el caso concreto de Galicia ha sido escasamente estudiada. E. Portela analiza la situación en la region del obispado de Tuy, encontrando como primera manifestación de la crisis la brusca contracción demográfica ${ }^{17}$, y con la constatación fundamental de la presencia de la epidemia de peste que asolaba Europa en 1348, documentada en Bayona por esas fechas ${ }^{18}$. Junto a esta crisis en la demografía, un segundo factor es el fuerte descenso de la producción agraria ${ }^{19}$. Estas mismas características de decadencia y crisis son generales en la zona al norte del dominio samanense, en el señorío de Santa María de Meira ${ }^{20}$ y más hacia el este, en la zona asturiana ${ }^{21}$. Podemos suponer, por tanto, que la generalizada crisis de subsistencia, las malas cosechas debidas a factores climáticos adversos y la enfermedad acompañaron también a los habitantes del dominio de Samos en la primera mitad de siglo. Este clima de desasosiego y, fundamentalmente, la presencia cercana de la muerte, fueron con toda seguridad factores decisivos en la aparición en la documentación de un tipo de mecanismo, la donación, que había comenzado a desaparecer casi por completo como medio para el engrandecimiento del dominio.

\section{1-a) Las donaciones}

Durante el período comprendido entre 1200 y 1325 se documentan en Samos un total de siete donaciones hechas por particulares al monasterio $^{22}$. Para un período bastante más reducido, el que ocupa este estudio, cincuenta y cinco años, tenemos un total de diez donaciones, de las cuales siete se encuentran concentradas entre los años 1348 y 1351, aquéllos que suponemos de mayor depresión y debilidad. Es este factor, la proximidad temporal, el que nos permite hablar de una causa común en estas donaciones: la profunda religiosidad de la población, acentuada seguramente por las predicaciones que ponderan la virtud y el valor de la limos na como medio para asegurarse la salvación en un momento como éste en que solicitan clemencia a Dios ante los males que los aquejan.

\footnotetext{
${ }^{17}$ Portela Silva, E.: La región del obispado de Tuy en los siglos XII al XV. Una sociedad en la expansión y la crisis. Santiago, 1976, pag. 278.

18 Portela Silva, E.: op. cit. pag. 279.

${ }^{19}$ Portela Silva, E.: op. cit. pag. 280.

${ }^{20}$ Mariño Veiras, D.: Señorio de Santa María de Meira (siglos XII-XVI). La Coruña, Nos, 1983, pags. 404-405.

21 Torrente Fernández, I.: El dominio del monasterio de San Bartolomé de Nava (siglo XIII-XVI). Oviedo, Universidad 1982, pag. 195.

22 Rodríguez Cancio, Ma.: op. cit. pag. 75.
} 
Nuestros documentos son parcos en fórmulas que nos permitan conocer las razones por las que se realizan esas donaciones: ni uno solo se sale de la fórmula habitual "dou et offerezco ao moesteyro de San Jullao de Samoos por la mia alma et de mia molher" 23 o "dou et offerezco por la mia alma et de meu padre et de mia madre" ${ }^{24}$. Sin embargo, es probable que esta repentina -aunque siempre relativa- afluencia de donaciones en estos cuatro años se deba a la posibilidad, por parte de ciertos pequeños campesinos, de haber aumentado su patrimonio a través de la incorporación de las propiedades de familiares fallecidos en los mismos años. La imposibilidad de cultivar por sí mismos estas tierras incorporadas las haría susceptibles de ser donadas al monasterio, o vendidas.

\section{1-b) Condición social de los donantes}

La importancia de los noblés y los grandes propietarios en las donaciones al monasterio de Samos ha quedado ya atrás; con esta desaparición, disminuye también la cuantía y amplitud de los bienes donados. Por tanto, estas donaciones no contribuyen a una mayor expansión del dominio del monasterio, un dominio que evolucionará tan sólo a través de las compraventas, factor que estudiaremos posteriormente.

En todos los casos de las donaciones estudiadas, presumimos que los autores son campesinos pequeños propietarios, salvo en una donación de $1325^{25}$, en que se trata de un miembro del estamento eclesiástico. En su mayor parte son los dos componentes del matrimonio, marido y mujer, los donantes. De estos donantes la documentación no nos permite conocer más que su condición de tales, salvo en este único caso ya citado. Esto parece ser algo frecuente en la documentación monasterial ${ }^{26}$. Tampoco podemos conocer su situación económica a través de la mención de las propiedades concedidas, ya que no sabemos si se trata de la totalidad de sus posesiones o tan sólo de una parte. De nuevo debemos citar la procedencia eclesiástica de nuestras fuentes como causa de esta parquedad de datos referentes a las condiciones campesinas. Sin embargo, es la devoción de estos desconocidos la que permite al monasterio acceder a la propiedad de los bienes que muy someramente estudiaremos a continuación.

\section{1-c) Bienes donados}

\footnotetext{
${ }^{23}$ A.H.N. Samos, carp. 1257, no 15 (2).

${ }^{24}$ A.H.N. Samos, carp. 1257, no 16.

25 A.H.N. Samos, carp. 1253, no 13-1.

${ }^{26}$ García García, M르.: op. cit. pag. 124.
} 


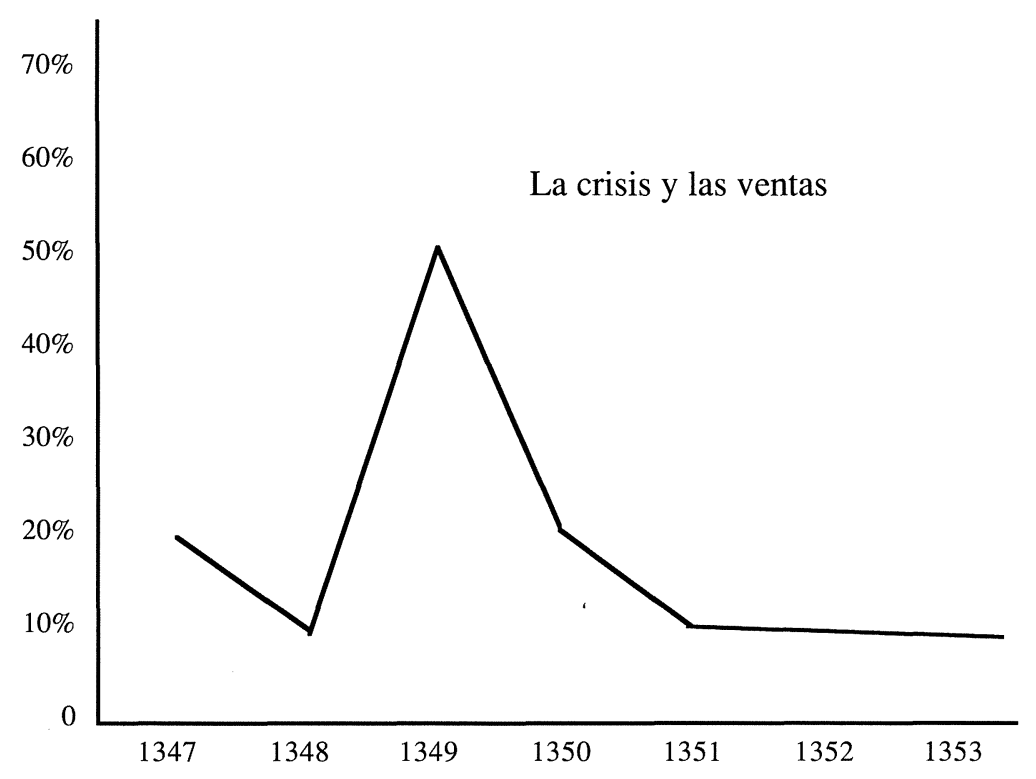

Porcentaje de ventas $1347-1353$

Al tratar de clasificar y estudiar los bienes adquiridos por Samos a través de las donaciones de este período, nos encontramos por primera vez con el problema de la imprecisión de los términos utilizados para calificar estas explotaciones cedidas al monasterio. Este es un tema aún no totalmente clarificado, a pesar de las innumerables aportaciones a su estudio. Los términos utilizados por los campesinos para definir sus propiedades en nuestras diez donaciones son los de heredad, heredamiento y casal, con sus fracciones. El término de heredad parece ser el más impreciso, pudiendo designar tanto un conjunto amplio de propiedades como una parcela ${ }^{27}$. En nuestro caso parece más factible la segunda acepción, al aparecer en nuestros documentos como un elemento más dentro de un conjunto de bienes que se donan, $y$, a menudo, en plural ${ }^{28}$ : la misma fórmula nos señala que se recibe más de una heredad. En cuanto al casal, siguiendo la definición de Portela Silva, se trata del "conjunto de tierras que una familia puede poner en explotación" 29 . La fragmentación de esta explotación a través de las transmisiones hereditarias se comprueba con la mención de las donaciones de fracciones de oytava do casal ${ }^{30}$ y novyna de

${ }^{27}$ según Portela Silva, E.: op. cit. pag. 136.

28 A.H.N. Samos, carp. 1258, no 12-2; A.H.N. carp. 1257, nº 16, A.H.N. Samos, carp. 1257, no 15 .

${ }^{29}$ Portela Silva, E.: op. cit. pag. 136.

"CUADERNOS DE ESTUDIOS GALLEGOS", Tomo XXXIX, Fascículo 104, Santiago 1991. 
casal $^{31}$, ejemplo del gran fraccionamiento del patrimonio, de localización dispersa por la misma razón.

No tenemos ningún dato que nos permita conocer el valor económico ni la dedicación de estos bienes cedidos; tan sólo una donación, del tipo denominado donación encubierta, nos da cierta información sobre el valor en que se tasan las propiedades que el monasterio recibe. Se trata de la donación por parte de un particular a un monje de Samos, Arias López (y no a la totalidad del monasterio) de varias heredades como único método para saldar una fiaduría contraída por su hermano, y por valor de ciento sesenta maravedíes ${ }^{32}$. No conocemos, desgraciadamente, ni el número concreto de heredades cedidas por estre precio ni si su extensión aproximada, problema con el que nos encontraremos cada vez que queramos evaluar con cierta precisión la importancia de los bienes incorporados al dominio del monasterio.

Podemos concluir con la constatación de que la importancia de este mecanismo de adquisición de bienes -la donación- es ya en este siglo casi nula, tanto por su escasez como por la poca extensión relativa de las propiedades incorporadas. El único factor que hace reseñable la constatación de la existencia de estas donaciones es su coincidencia cronológica en un período muy corto, de 1348 a 1351, y con una afluencia que nos pone en la pista de la situación demográfica y social grave que vivía la totalidad de la región gallega y el dominio de Samos a mediados del siglo XIV.

\section{2- Las compraventas}

\section{2-a) Motivos}

La iniciativa "empresarial" del monasterio de Samos se hace patente a través de las compraventas realizadas en este período. Así como en las donaciones el monasterio no tiene un papel ejecutor importante, no ocurre así con los mecanismos cuyo estudio iniciaremos de aquí en adelante, las compraventas y las permutas. Con ellos el monasterio redondea sus posesiones o las amplía en aquellas zonas que económicamente le interesan, poniéndolas en explotación posteriormente a través de los contratos de foro.

En nuestro intento por conocer la evolución del dominio de Samos debemos volver a referirnos a la incidencia que la crisis de mediados del

30 A.H.N.Samos, carp. 1259, no 2 .

31 A.H.N. Samos, carp. 1258, no 12-2.

${ }^{32}$ A.H.N. Samos, carp. 1253, no 13-1. 
siglo XIV pudo tener en la concentración de estas compraventas en los años que van de 1347 a 1355 , pero fundamentalmente, tal como vemos en el gráfico de la página 31, en el período 1347-1350. Este comienzo de las ventas por parte de los campesinos antes de la culminación de la crisis en 1348 con la llegada de la peste tiene que ser puesto en relación con las referencias a un período de malas cosechas y carestía que 'preparó" a la población para la rápida expansión de la enfermedad. Esta carestía aparece frecuentemente citada en las fuentes castellanas, precedida por años de malas cosechas a causa de la adversidad del clima ${ }^{33}$. La evolución anterior de las compraventas del monasterio de Samos nos reafirma en nuestra creencia de la importancia de la crisis como factor desencadenante del proceso; durante el siglo XIII, hasta 1275 , no se constatan apenas; un segundo período, con un incremento considerable en la última década de siglo, y finalmente un descenso brusce en las compras, que desaparecen por completo al llegar a la fecha de $1308^{34}$.

Los intereses del comprador, el monasterio, son, como ya hemos citado, el intentar completar sus propiedades en ciertas zonas en las que está especialmente interesado y en las que ya ha establecido su dominio. Junto a ello, suponemos que aprovecha la coyuntura favorable que presenta el hecho de que los vendedores, los campesinos, pasen por dificultades económicas y tengan necesidad de numerario.

\section{2-b) Condición social de los vendedores}

$\mathrm{Al}$ estudiar este mismo problema en el caso de aquellas personas que ceden propiedades al monasterio en donación, hemos citado ya las dificultades con las que nos encontramos para poder conocer algo sobre la realidad de estos protagonistas de las ventas. Faltan, algo ya común, alusiones a nobles o grandes propietarios. Solamente tenemos alguna noticia de aquéllos, que, por el hecho de ser clérigos, su condición es citada en el documento correspondiente ${ }^{35}$, o el caso de Rodrigo Alonso, mencionado precisamente por ser criado de un clérigo ${ }^{36}$. El hecho de considerar a estos vendedores como campesinos pequeños propietarios, por razón de ser los autores de estas ventas al monasterio y al no ser mencionado ningún otro dato que pudiese dar lugar a una diferente clasificación, es arriesgado: no podemos conocer la cuantía de sus posesiones ni si situación económica -que suponemos difícil- en el momento de sus ventas; sin embargo, nos parece suficientemente ilustrativo el hecho de la concentra-

\footnotetext{
33 Torrente Fernández, I.: op. cit. pag. 197.

${ }^{34}$ Rodriguez Cancio, MR.: op. cit. pag. 78.

${ }^{35}$ A.H.N. Samos, carp. 1254, no 17; carp. 1257, nº 10 (1)-2; carp. 1258, no 7 (1)-2.

${ }^{36}$ A.H.N. Samos, carp. $1258, \mathrm{n}^{\mathrm{o}} 7$ (1)-4.
} 
ción de estas compraventas en un período cronológico corto y concreto. Observamos también la venta de ciertas propiedades por parte no de una sola persona, sino de varias, hermanos en la mayor parte de los casos, el conjunto de los herederos, quienes, como E. Portela apunta ${ }^{37}$, parecen compartir una especie de propiedad colectiva sobre estas parcelas, ya compartimentadas en anteriores transmisiones hereditarias ${ }^{38}$. En algunas de las ventas, esta compartimentación ha alcanzado un grado más, al aparecer en la lista de vendedores, no sólo los hermanos, sino también sobrinos de éstos ${ }^{39}$, hijos de alguno de los propietarios originarios que ha dividido ya su parte, al morir, entre sus herederos.

\section{2-c) Bienes objeto de compraventa}

Es éste un tema interesante ya que a través de su estudio podremos intentar conocer los intereses concretos del monasterio por zonas geográficas y tipos de propiedades, más o menos aptos para cierto tipo de cultivos. Podremos preguntarnos, de esta manera, si existía una política económica real dirigida por el monasterio, y una actuación consecuente con ella.

Es algo común, y particularmente útil a la mejor explotación y control de las propiedades, el que el monasterio intente ampliar o completar sus

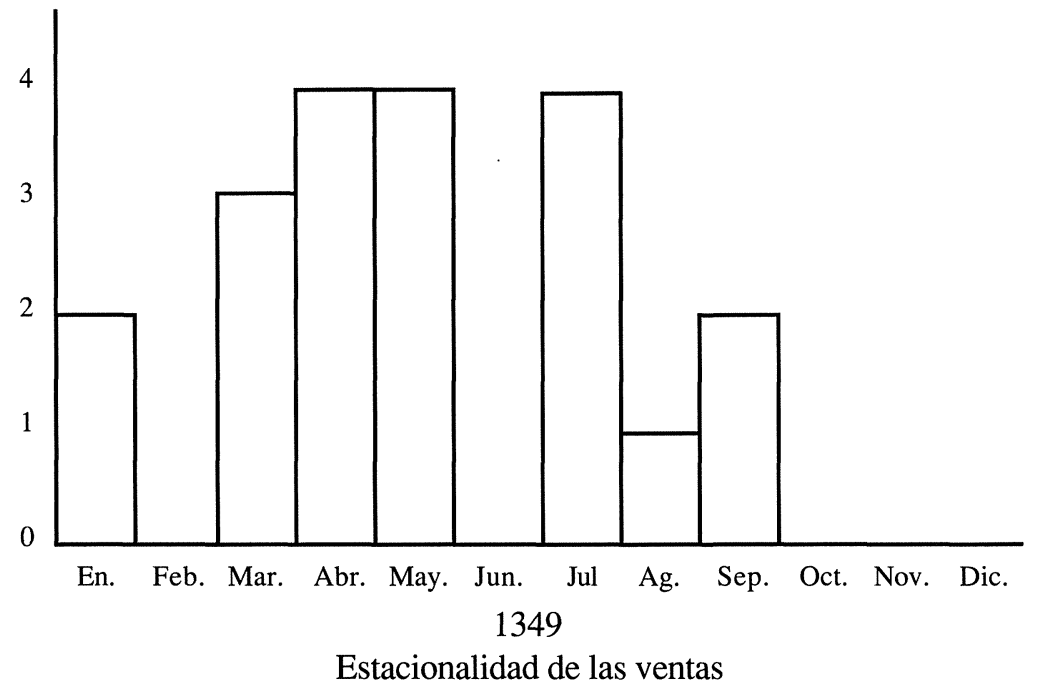

${ }^{37}$ Portela Silva, E.: op. cit. pag. 138.

38 A.H.N. Samos, carp. 1256, nº 18; carp. 1257, no 9-2; carp. 1258, no 5 (2); carp. $1257, \mathrm{n}^{\circ} 13,(1)$; carp. $1257, \mathrm{n}^{\mathrm{o}} 11-2$; carp. $1258, \mathrm{n}^{\mathrm{o}} 5$ (1); carp. $1258, \mathrm{n}^{\mathrm{o}} 11$; carp. $1258, \mathrm{n}^{\mathrm{0}} 3$ (1)-1.

${ }^{39}$ A.H.N. Samos, carp. 1258, no 5 (2)-3. Carp. 1258, nº 11. 
posesiones en la zona circundante y en aquellas zonas en las que se encuentra asentado con anterioridad; en la zona cercana a Samos, las compras son importantes: en Parada, Santo Isidro, Bustofrío, o Gontán, Seoane de Louzara, etc. Lo mismo ocurre con el área de Sarria, en la que el monasterio ya tenía posesiones: compran ahora en Fontao, Pacio, Santiago de Barbadelo y Reente. Dos zonas de interés para el monasterio, como son Quiroga y Saviñao, también son lugares de ampliación de las posesiones de Samos. Pero es especialmente llamativa la concentración de buena parte de las compras efectuadas por el monasterio en la zona del Bierzo cercana a Villafranca. Todas las adquisiciones del monasterio en el año de 1347 se realizan allí, en total de siete. Tan sólo en dos de ellas, sin embargo, se alude a lo que creemos motivo para el gran ihterés del monasterio por la comarca del Bierzo: se trata de la compra de dos viñas, y consideramos probable que el resto de las propiedades adquiridas fuesen cedidas posteriormente con la condición de que se plantase viña ${ }^{40}$. Esta política de imposición del cultivo de la vid en tierras anteriormente dedicadas a otros productos está en consonancia con lo que ocurre en otras zonas gallegas, como en el obispado de Mondoñedo ${ }^{41}$, en aquellas tierras abandonadas en la primera mitad de siglo a causa de la crisis.

La importancia del cultivo de la viña en los monasterios benedictinos tiene su origen en la propia regla de San Benito, que contribuye a propagar unos cultivos determinados en los que la vid destaca como esencial, junto a los cereales ${ }^{42}$. Aparte de estos motivos que podríamos llamar rituales, podemos suponer que los motivos económicos pesaban también a la hora de destinar grandes extensiones a un cultivo que supone grandes trabajos y gran cantidad de mano de obra, además de favorables condiciones climáticas que a veces no se encontrarían en algunas zonas del dominio: es probable que los excedentes de una producción más que suficiente para las necesidades del monasterio se destinaran a la comercialización en las villas cercanas. No debemos olvidar que el monasterio se sitúa en una de las vías alternativas del Camino de Santiago. Esta política de comercialización del vino era seguida también por otros monasterios ${ }^{43}$.

En cuanto a la temporada de las compras, la hipótesis de J.A. García de Cortázar, seguida en muchos estudios ${ }^{44}$, considera como mayoritarias

\footnotetext{
${ }^{40}$ A.H.N. Samos, carp. 1260, $\mathrm{n}^{\circ} 8$.

${ }^{41}$ Rodriguez Galdo, Mำ ${ }^{\mathrm{a}}$.: Señores y campesinos en Galicia, siglos XIV-XVI. Santiago, Pico Sacro, 1976, pag. 93.

42 Duby, G.: Guerreros y campesinos. Desarrollo inicial de la economía europea (500-1200). Madrid, Siglo XXI, 1979, pag. 23.

${ }^{43}$ Rodriguez Galdo, MํX.: op, cit. pag. 97.
} 
las compras hechas en primavera, ya que es la época en que los campesinos necesitan invertir numerario en simiente para la nueva siembra o tienen dificultades económicas debidas a la estación. No es éste nuestro caso. Tal como muestra el gráfico de la página 34 , las compras se distribuyen irregularmente durante nueve meses al año, de enero a septiembre, con un máximo en el mes de julio; quizá en este caso, la excepcionalidad de la situación -de crisis generalizada y continua- impida la observación de este fenómeno de estacionalidad en el proceso de compras: los campesinos se encuentran con una necesidad constante de hacer frente a los problemas económicos, siendo sus dificultades mayores que las habituales del período marzo-mayo constatadas por García de Cortázar. Otro factor a tener en cuenta es la posible disponibilidad por parte del monasterio de numerario para efectuar las compras. En el caso de Samos, parece que se encuentra en una muy buena situación económica, sin problemas aparentes para efectuar un desembolso como el de 1348, de 2890 maravedíes.

Los bienes que constituyen objeto de compraventa son de muy diferente denominación y tipo. Predominan fundamentalmente las heredades, con un 24,5\% del total de los bienes adquiridos, y las leiras de heredad, con un $20,7 \%$, seguidos de las leiras $(16,9 \%)$ y finalmente las leiras dedicadas especialmente al viñedo - leiras de viña- con un $11,3 \%$. Todos estos nombres se refieren a explotaciones familiares provenientes de la parcelación de unidades más amplias.

\section{2-d) Valor de los bienes}

Un estudio en profundidad del valor real de las diferentes propiedades adquiridas por el monasterio resulta una tarea imposible al faltarnos datos tan esenciales como la superficie de los bienes incorporados. Junto a ello, las oscilaciones de los precios de las propiedades, incluso de aquéllas con la misma denominación y cuya compraventa se efectúa en el mismo período cronológico, son tan brutales que hacen considerar a algún autor que se trata de cantidades simbólicas ${ }^{45}$. Sin embargo, creemos que alguna diferencia esencial, en el tipo de propiedad, su tamaño o importancia,

\footnotetext{
${ }^{44}$ así ocurre con los siguientes: Durany Castrillo, M.: San Pedro de Montes. El dominio de un monasterio benedictino de El Bierzo. Instituto Fray Bernardino de Sahagún, CSIC, 1976, pag. 136. Gavilán, E.: El dominio de Párraces en el siglo XV: un estudio sobre la sociedad feudal. Zamora, Junta de Castilla y León, 1986, pag. 193. Torrente Fernández, I.: op. cit. pags. 75-76.

${ }^{45}$ tal es el caso de Díez Espinosa en su estudio sobre el monasterio de Santa María de Palazuelos. Estas oscilaciones son constatadas también por E. Portela: op. cit. pag. 136.
} 
debe existir entre los heredamientos que el monasterio de Samos compra en 1348 por 2200 maravedíes ${ }^{46}$ y los heredamientos que en este mismo año compra por $420^{47}$.

Se estipulan en dinero todas las compraventas efectuadas por el monasterio durante estos años, pagándose todas en maravedíes, especificándose en casi todos los casos que se trata, bien de moneda del rey Alfonso, bien de moneda de a ocho sueldos cada una; en algunos casos se nos hacen ambas precisiones. Este interés -que también se constata en los contratos de foro- está en clara relación con la preocupación por las frecuentes oscilaciones de la moneda.

Los precios, como ya hemos señalado, varían de manera irregular, sin poder extraerse conclusiones definitivas sobre el valor de la tierra ni sus variaciones a lo largo de estos cincuenta y cinco años. Tan sólo hemos podido hallar un precio medio de dos tipos de propiedades, de entre aquéllas más comunes en estas compraventas estudiadas ${ }^{48}$. Las leiras de heredad, de las que el monasterio adquiere un total de once, fluctúan entre 12 maravedíes, la más barata, y 45 , la que alcanza un precio más alto; el precio medio sería de 26,9 maravedíes. En cuanto a las leiras de viña, su precio es mucho más elevado, factor que podemos poner en relación con ese interés que ya hemos señalado por parte del monasterio con respecto al viñedo y la posterior comercialización del excedente de vino. El precio medio de las seis leiras de viña adquiridas es de 63,8 maravedíes.

Finalmente, debemos señalar la inexistencia de compraventa alguna de bienes urbanos, como casas, tiendas, hornos, etc., algo muy frecuente en otros monasterios ${ }^{49}$ y que sin embargo no debemos tomar como una muestra del carácter predominantemente rural del dominio de Samos, al existir menciones de este tipo de propiedades en la documentación que estudiaremos seguidamente.

\section{3) Las permutas}

Es éste un mecanismo interesante, ya que si bien su importancia como elemento de ampliacion de las posesiones del monasterio es muy reducido -se ceden unas propiedades a cambio de otras-, vuelve a ponernos

\footnotetext{
${ }^{46}$ A.H.N. Samos, carp. 1257, $\mathrm{n}^{\mathrm{o}} 5$.

47 A.H.N. Samos, carp. $1257, \mathrm{n}^{\circ} 7$.

${ }^{48}$ Resulta imposible cuantificar el número de propiedades adquiridas por el monasterio en el caso de los heredamientos, heredades y viñas, por aparecer en los documentos en fórmulas como toda quanta heredad nos avemos en ... que hacen imposible el saber de cuántas piezas se trata; no ocurre así en los casos estudiados, las leiras de heredad y las leiras de viña, en los que se especifica el número que se cede en la compraventa.

${ }^{49}$ Mariño Veiras, D.: op. cit. pag. 65.
} 


\begin{tabular}{|c|c|c|c|c|c|c|c|}
\hline \multicolumn{8}{|c|}{ Adquisición de bienes rurales mediante compraventa } \\
\hline & $\begin{array}{l}1325- \\
1329\end{array}$ & $\begin{array}{l}1330- \\
1339\end{array}$ & $\begin{array}{l}1340- \\
1349\end{array}$ & $\begin{array}{l}1350- \\
1359\end{array}$ & $\begin{array}{c}1360- \\
1369\end{array}$ & $\begin{array}{c}1370- \\
1380\end{array}$ & TOTAL \\
\hline Heredamientos & & 1 & 3 & & & & 4 \\
\hline Heredades & & & 7 & 6 & & & 13 \\
\hline Leira de heredad & & & 10 & 1 & & & 11 \\
\hline Leira de viña & & & 3 & 2 & 1 & & 6 \\
\hline Leira & & & 7 & 2 & & & 9 \\
\hline Viña & & & 1 & 2 & & & 3 \\
\hline Parte de viña & & & 3 & 1 & & & 4 \\
\hline Parte de heredad & & & 1 & 1 & & & 2 \\
\hline Parte de leira & & & 1 & & & & 1 \\
\hline Total & & 1 & 36 & 15 & 1 & & 53 \\
\hline
\end{tabular}

sobre la pista de los intereses concretos del monasterio por hacerse con bienes en zonas particulares y por abandonar otros que ya no son tan provechosos. Es sin embargo un mecanismo que se utiliza ya de forma escasa en el período anterior a nuestro estudio, de 1200 a 1325,50 . En cuanto al período que nosotros estudiamos, el número de permutas es de tres, realizadas dos de ellas con dos monasterios. La primera, realizada en 1333, resulta interesante por la constatación del interés de Samos por hacerse de nuevo con propiedades en la zona del Bierzo en una época anterior a las compraventas generalizadas que ya hemos señalado. El convento de Belvís, pues con él se realiza este cambio, cede al monasterio sus propiedades en Villafranca del Bierzo: estas propiedades consisten en heredamientos, casas, casares, lagares, bodegas, cubas, etc. ${ }^{51}$ Samos, en cambio, cede a Belvís sus heredades, viñas, casas en San Julián do Mar, y la iglesia de san Salvador de Colantres, en la villa de Betanzos.

La otra permuta se realiza con el monasterio de San Lorenzo de Carboeiro, cediendo éste la iglesia de San Pedro de Incio con todas sus per-

${ }^{50}$ Rodríguez Cancio, Mar.: op. cit., pag. 87.

${ }^{51}$ A.H.N. Samos, 'carp. 1253, no 20 (1-2). 
tenencias ${ }^{52}$, y entregando Samos a cambio las iglesias de Santiago de Fontaos y la de San Miguel de Orça.

El monasterio, por tanto, no experimenta cambios sensibles a través de este mecanismo, ni cuando se trata de permutas con otros dominios monasteriales ni, caso del tercer cambio, cuando éste se realiza con particulares $^{53}$.

\section{CONCLUSIÓN}

Ya en el final de nuestro estudio, debemos volver atrás para intentar, a modo de conclusión, recapitular aquellos datos más interesantes que definan la situación del dominio del monasterio a través del período de cincuenta y cinco años que hemos perfilado.

Para conocer su evolución en estos momentos nos hemos acercado a aquellos mecanismos que la documentación recoge y que pueden producir cambios en la extensión e importancia de ese dominio; son éstos las donaciones, las compraventas y las permutas.

En cuanto a las donaciones constatamos cómo, a pesar de su escasa importancia en relación con signos anteriores, en los que era un mecanismo decisivo para la incorporación de nuevas propiedades, hay un cierto resurgir que debemos poner en relación con esa situación de crisis que sufre toda la sociedad gallega a mediados del siglo XIV y que afecta también a la zona de Samos. Este resurgir de las donaciones tiene su valor ideológico y como constatación de la crisis, pero escaso valor económico para el engrandecimiento del dominio.

Un panorama totalmente diferente nos lo presentan las compraventas que el monasterio efectúa, fundamentalmente en la década que va de 1340 a 1349; estas ventas, realizadas por un campesinado al que suponemos empobrecido y con necesidad de numerario, nos hablan, en primer lugar, de la buena situación económica en la que se encuentra el monasterio, que cuenta con medios para realizar toda esta política de compras en el momento adecuado, y de un campesinado que, aparte de una situación crítica que le obliga a vender, cuenta con unas propiedades que parecen no serle totalmente necesarias, al ser objeto de venta. ¿Es esto un signo de despoblación, de que no existen brazos suficientes para trabajar un terrazgo amplio? No nos atrevemos a asegurarlo, al no constar otros argumentos que nos reafirmen en esta hipótesis.

Otro mecanismo que recoge también la documentación de Samos en este momento es el de las permutas o cambios, que por su escaso núme-

\footnotetext{
${ }^{52}$ A.H.N. Samos, carp. 1253, no 14.

${ }^{53}$ A.H.N. Samos, carp. 1261, no 15.
} 
ro no son relevantes, pero que demuestran la existencia de una política económica concreta por parte del monasterio, al menos en cuanto a la elección o interés por zonas concretas, como el Bierzo, debido a su dedicación a un cultivo muy interesante y rentable, la viña.

Por todo esto consideramos que Samos ha acertado a paliar de manera eficaz los efectos de la crisis en estos años posteriores a la década central del siglo; parece ponerlo en evidencia la penetración clara de la economía monetaria en el dominio monasterial - ya hemos visto cómo todas las compraventas se estipulan en dinero-y la transformación de una buena parte de sus tierras a través de una creciente especialización vitícola: buena muestra de ello es el interés del monasterio en la cercana región del Bierzo y la compra de nuevas heredades que inmediatamente pasan a ser puestas en explotación con un único cultivo - la vid-. 